\author{
The International \\ Journal of Art \& \\ Design Education
}

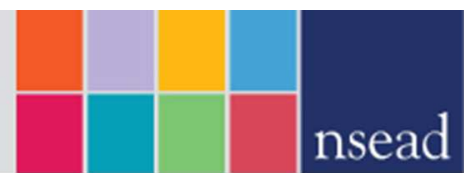

\title{
International students and ambiguous pedagogies within the UK Art School
}

\begin{tabular}{|r|l|}
\hline Journal: & The International Journal of Art \& Design Education \\
\hline Manuscript ID & Draft \\
\hline Manuscript Type: & Original Article \\
\hline Keywords: & international, ambiguity, art, school, implicit, values \\
\hline Abstract: & $\begin{array}{l}\text { This paper will consider the tensions and opportunities provoked by the } \\
\text { presence of a growing number of international students at UK art schools } \\
\text { in which ambiguity operates as an implicit value within fine art pedagogies. } \\
\text { Challenging assumptions of lack or deficit this paper will ask how } \\
\text { responding to this changing student body might require thinking beyond } \\
\text { the horizon of normative claims and attitudes of the art school toward a } \\
\text { situation in which it is constituted through the divergent perspectives of its } \\
\text { students. Furthermore I suggest this requires the art school to address } \\
\text { with greater commitment it's pedagogical dimension in order to live up to } \\
\text { it's 'promise' as a heterotopic space. }\end{array}$ \\
\hline
\end{tabular}




\section{International students and ambiguous pedagogies within the UK art school}

\section{Goldsmiths College, 2008}

In 2008 I undertook a Masters in Fine Art in which I shared a critical seminar group with a Taiwanese student named John. John was no doubt attracted to this programme for similar reasons to myself- the MFA promised to be what Alec Shepley recently described as the 'heterotopia' of the art school; a place for contestation and difference (Shepley 2016). For much of the course John's work was characterized by a preoccupation with the clash of culture he found himself within, negotiating language and mis-communication via single shot fixed camera videos in which scenarios were performed and edited to create further mis-translations to sometimes humorous effect. Conceptually clear, over the course of two years the work was, however, consistently criticised for being "too direct", "too apparent" and "too obvious". Yet, in the last seminar, John's work made something of a turnaround; in the centre of the room was a messy sculptural assemblage, with found materials precariously piled around a rotating desk fan, occasionally blowing a hanging piece of silk behind which was revealed an empty packet of Taiwanese food protruding from a hole in a piece of wood. The piece was playful and quite lovely, but most interestingly, this work elicited unanimous approval from the group. It was as if his work had finally achieved an ideal state of contemporariness- sexy, ambiguous and subtlety critical (but not too much). It was if John had finally 'got it', understood the brief and was now ready to participate in the contemporary art world. And not a moment too soon!

During the weekly critiques I often found myself thinking about the unfolding situation through the lens of my 'other' role as a teacher, and in many ways these weekly critiques, in which struggles for legitimacy were laid bare, informed my current 
research into the contingencies of the art school today. During this last session what intrigued and perplexed me in equal measure was how the uniform praise this work received revealed an unspoken consensus underpinned by a quite specific set of values, that were all the more striking for their lack of direct address. The adherence to these values, adherence to which reflected the deeply adhered to boundaries and exclusions that, for Pierre Bourdieu, regulate any particular field as "a structured space with its own laws of functioning and its own relations of force" (Bourdieu, 1993).

This paper explores these values with particular attention to the experiences of international students at BA and MA level. I would like to address this growing student body in terms of tensions raised, yet rather than attribute a deficit problem to these, the 'problem' of the international student, or the inadequacies of fine art programmes for failing to adapt, I want to position these tensions as ruptures to established paradigms, that might offer something akin to Badiou's notion of an event (den Heyer, 2010). In doing so I hope to show how the presence of international students make the implicit values of fine art pedagogies palpable, knowable, and in doing so can reveal the horizon of our own orthodoxies.

\section{Deficit Model}

Recent years have seen a growing number of international students in Higher Education across all subject areas. The United Kingdom is the second most popular destination after the USA for international students travelling from countries as far and wide as Chile, Malaysia, Pakistan and Taiwan and art and design courses are amongst the most popular: University of the Arts London is perhaps emblematic of this shift enrolling more than four times the numbers of international students than the next most popular course at any other UK university (HESA 2013). This growth of internationalisation 
reflects both the subjection of education to market forces and the widening of access concomitant with globalization. And, as with any changed condition, universities are faced with the challenge of accommodating students for whom negotiating entirely new systems of academic education, language and culture can be inhibiting and destabilising (Ryan 2011).

Yet universities are slow institutions, so responses to these new conditions vary greatly, and in some cases the need for change is met with resistance leading to a compromised teaching and learning experience. Furthermore, the perceived complexities presented by international students can contribute to cynical assumptions, embodied by tabloid headlines reproaching universities for 'cashing in' on wealthy 'Asian' students, when the body of students is as diverse as 'international' suggests, encompassing countries that not only differ enormously from one another demographically and culturally but within which there is also great diversity. But perhaps most relevant here are the misconceptions of international students' abilities to learn within the UK system based upon a pervasive deficit model within which they are characterized as passive, lacking adequate critical thinking and independent learning skills (Ryan 2011). Underlying this are beliefs that they need to 'catch up' with 'our' methods, approaches and values, beliefs that can at worst constitute a subtle yet systemic cultural imperialism.

Within the 'discipline' of fine art the potential for lack of clarity is even greater. Fine art's place within the university system has long been contested, with processes of learning characterized by inference, suggestion and iteration, and forms of knowledge production quite at odds with traditional academic structures: so much so that some art schools such as the Slade reject the national modular framework to which other subjects and universities are tied, thereby operating according to a different system and different 
rules. This identity of difference can be firmly placed within an historical lineage of contestation, from the art school's assimilation into the university system in the 1990's, its integration into the polytechnic system in the 1980's and prior to that the standardizing effects of national qualifications; a series of shape shifts that at each stage has prompted resistance and even protest (Tickner 2008). So, whilst in recent years the art school has been subjected to the same regulatory processes as every other subject area, it still maintains an identity of otherness and difference. Indeed this difference constitutes part of the mythology of the art school; it does not operate according to the normative codes of education, something 'else' happens there (Craig-Martin, 2015).

This otherness is justified, perhaps, by the field of art itself, in which ambiguity could be considered a defining feature. Elisabeth Fisher and Rebecca Fortnum's edited book On Not Knowing, presents a collection of chapters that address the specificity of art as a form of research. The book opens by describing art practice as a 'liminal space where not knowing is not only overcome, but sought, explored and savored; where failure, boredom, frustration and getting lost are constructively deployed' (Fisher \& Fortnum 2013). In a lecture titled 'Ambiguity', Sally O'Reilly traces its roots to the Enlightenment era as a countering tendency to the rational world's inclination toward measurement and taxonomy via the truth seeking disciplines of science, law, finance and, later, bureaucratised labour, from which art's ambiguity offered an 'evocative retreat' (O'Reilly, 2015). And whilst these deemed rational disciplines have, arguably, since become wholly ambiguous- see Adam Curtis's 2014 Bitter Lake for prescient example- such not knowing is endemic to the field of contemporary art; from exhibitions that 'cultivate uncertainty and conscious incompleteness, ${ }^{\mathrm{i}}$ to those that seek a turn away from a critical distance that has been dominant within art practices since the 
1960 's. ii If ambiguity is a defining feature in the field of art, how is it encountered within the pedagogies of higher education?

\section{Negotiating Pedagogies of Ambiguity}

Mind the Gap: Expectations, Ambiguity and Pedagogy within Art and Design Higher Education (Austerlitz et al 2009) is a comprehensive study undertaken across several universities globally that examines the relationship between student achievement and social background in undergraduate art and design courses by revealing the implicit values and orthodoxies of art and design pedagogies. The study demonstrates how success within the field of art and design is contingent upon familiarity or cognisance with these values, and maps these relations onto social class. Whilst it does not directly address the international student, and looks beyond fine art to the broad spectrum of art and design, the implications are far reaching in terms of revealing the effects of specific implicit values and who these values might privilege.

The study defines teaching within art and design programmes as characterized by 'a pedagogy of ambiguity, where skills are not simply competencies, but the ability to operate in the complexities of uncertainty' (Austerlitz et al 2009) a pedagogy that promotes creativity as a by-word for risk taking, innovation and embraced uncertainty. These values are manifest in a number of ways. Whilst Fine Art courses often commence with a structured phase of material based experimentation, by the end of the first year most operate with a studio practice format of self-directed study facilitated by one to one tutorials and group critiques. Within this open format students are expected to 'synthesise independent research' within their practice, take 'creative risks', produce 'innovative, experimental outcomes' and operate in an atmosphere of 'radical uncertainty' (University of Westminster Course Handbook, 2012). Indeed, these are the 
values that art schools pride themselves on, and that constitute a package that has global currency today manifest in the 'thriving' creative industries (Banks 2007).

Austerlitz et al found that there is a tendency amongst some students to accept this ambiguity wholesale, confident that this is just part of an unexplainable but understood logic of the art school. These are, perhaps, the students whose voices are the loudest in lectures, who ask questions and challenge tutors and are more present in the semiprivate, and for many highly boundaried, space of the staff room. It is those with confidence in the languages and codes of this field, or sufficient 'cultural capital' who will thrive, whereas those unversed in these languages and codes, thereby lacking in this capital, may not (Bourdieu 1993). As Austerlitz et al demonstrate, for those students unfamiliar with the benefits of risk and for whom uncertainty feels far from a necessary, productive state these implicit values can be met by confusion and diminished confidence. A telling vignette exemplifies this- wherein a perplexed parent contacts a course leader to complain about their daughter's lack of direction or sense of progress within the course, to which the tutor responds by saying that this is the point, that not knowing is a necessary part of the learning experience. Very different values are at play between those deemed normative at school, within the family context and the university, and yet the student is expected to 'navigate through the difficulty of ambiguity as a kind of initiation, which he will pass or fail based on his strength of character' (Austerlitz et al 2009).

If we consider the introduction and later uncapping of fees since 1998, the contingencies of a logic of risk and uncertainty become even more pronounced, prompting for some, understandably 'an added resistance to risk, particularly for students who may have made a larger investment of economic and symbolic capital' 
(Austerlitz et al 2009), or for those with more at stake in the event of failure. Yet even measures of success and failure are inherently complicated by the ambivalent and contradictory attitudes toward assessment in fine art. On fine art programmes, grades and assessment procedures are sometimes denounced as a necessary evil, reflecting a trenchant bureaucracy that has been imposed upon the freedoms of the art school. However the actual currency of achieving a first class degree tells a different storyfought for by championing staff, displayed on the CVs of ambitious students and expected by demanding parents. For the many international students whose study abroad has only been made possible through scholarships, and for whom success is part of a contractual bind, the prospect of 'failure' is confusing at best, and at worst diametrically opposed to the very security that so many undertaking higher education hope to achieve.

O'Reilly's lecture on Ambiguity opened by expressing suspicion toward an unquestioning valuing of 'specific and coded ambiguities' that actually disguise vagueness within modern art discourse (O’Reilly 2015). Similarly, Mind the Gap concludes by distinguishing ambiguity in terms of a specialized value necessary to the discipline and ambiguity in terms of obfuscation and vagueness that serves no end but to protect embedded values at the cost of contributing to processes of exclusion.

\section{The bureaucrat at the table}

Recently I spoke with a curator about the conditions of higher education today- agreeing that a pervasive neoliberalism and instrumentalisation of education has led to success becoming overly equated with economic value, creating a situation whereby art school was becoming led by a culture of professionalisation, networking and preparation for the market. We also agreed that this led to a situation where art education was in danger 
of functioning according to a pre-existing logic or rationale, when art and art education have the potential to question and confront this logic. So far so good.

To offer another perspective I then introduced the issues raised in Mind the Gap, whereby fine art's own 'normative values' of ambiguity, 'not knowing' and risk could, if left unexamined, serve some students better than others, and that it might be important to consider for whom our dearly held values might privilege. How can widening participation occur, I went on to ask, if the teaching within fine art programmes is not held to account? This was not received so well, and instead elicited a look of such incredulity that I felt like a bureaucrat at the table, overly concerned with access and student numbers above and beyond the subject itself, and far from the mysterious laws of the art world. For the curator, art education should be ambiguous and not 'dumbed down' to function as a means to acquire a normative idea of stability and security; art should promote other ways of being in the world.

The conversation troubled me, as in many ways I agree with him. Art and art education can offer different ways of being, questioning and producing in the world- this after all is what drew me to art school in the first place. Practice affords ways of negotiating a world that is ambiguous, precarious and uncertain. Yet it is telling that my raising of these issues provoked such a rebuttal, perceived perhaps as an instrumentalist need for clarity. To speak of widening participation, teaching, pedagogy is inherently un-sexy, and the art school is a very sexy place. At the heart of this is, I believe, a subtle disavowal of pedagogy within the discipline of fine art in higher education. And despite recent attention to education within art discourse ${ }^{\text {iii }}$ the art school remains somehow exempt from direct address of its pedagogical approaches. It is as if too much analysis or overthinking of this will threaten its very USP. As the title of James Elkin's book 
Why Art Cannot be Taught (2001) suggests, such notions are bound up with a sustained adherence to a Western, Romantic model of the artist as special, and the art school as where the gifted 'rise to the top' (Elkins 2001).

The problem, however, lies less with resistant tutors, clinging to tried and tested orthodoxies, than a more deeply embedded set of attitudes and values that, under the conditions of the neoliberal university today, there is little time to reflect upon, let alone challenge or transform. As with so much public sector work, time for reflection on curricula content and it's possible development is diminished by the processes of bureaucracy, individualization and pressure to demonstrate competencies so as to justify scarce and precious research time. And whilst visiting lecturers can introduce new ideas, the increasingly flexible, part-time nature this work prevents any purchase on the established ways of a course. As lunchtimes are reduced to rushed sandwiches at the desk, less time is available for established staff to reflect upon and discuss pedagogies and exactly what and how it is that we teach. The willingness is no doubt there, but for willingness to become action there needs to be time to identify a problem.

\section{UCL Institute of Education, 2016}

I have taught at the Institute of education on the MA Art \& Design in Education since 2013. The student cohort is largely made up of art teachers who work across various levels and contexts of education; from primary and secondary school teachers to further and higher education lecturers and museum and gallery educators. The students enrol on the programme for a variety of reasons, some to focus on a specific area of research, some to re-engage with a diminished practice and others to simply step back from what seems like an impossible situation under the pressures of excessive measurement. The programme has recently experienced an increased number of international students and 
as such what was once a part-time course primarily aimed at schoolteachers has become a mixed mode course with more than half of students enrolled on a full time basis.

Teaching on the MA Art \& Design in Education has heightened my awareness to the ways in which our relationship to art is constituted through myriad experiences of institutions and educational paradigms. The course commences with a studio practice module in which students are asked to consider their own relationship to teaching and learning. This requires reflection of their previous experience as learners, as well as teachers, of art and design, prompting a process of revelation in which 'shaping educational paradigms' become apparent. The students are also encouraged to reflect upon the position of being a learner and, as tutors on the course, neither we nor the values and methodologies of the MA are exempt from this process; our own academic culture also constituting 'systems of belief, expectations and practices about how to perform' (Cortazzi \& Jin 1997).

The students develop research through an identification of tensions, dilemmas and issues that arise through this process of reflection. In recent years the course has facilitated practice and research that ranges from; teaching as form of choreography in relation to performance measures of the Chilean schooling system; the development of an expansive architectural-materialist practice as alternative to the religious holiday object making ubiquitous in Greek art education; an examination of the ways in which Ai Wei Wei conforms to a uniquely Western paradigm of the autonomous artist; the creation of a psycho-geographical audio tour of a British school building, and an exploration of notions of failure and success in relation to experiences of higher education in Korea and at University of the Arts, London. These practices tell us about art and design and how they are constituted globally today. Furthermore, they embody 
modes of research that employ risk, not knowing and ambiguity to negotiate specific realities, situations and orthodoxies. As Mind the Gap suggests, overcoming the limitations or exclusions of ambiguous pedagogies is not about simply making the implicit, explicit; ambiguities are important, for Pablo Helguera constituting one of art's ‘teachable moments' (Helguera 2011).

O'Reilly refers to the multifocal nature of perception, the necessity of taking on board multiple perspectives in our understanding of the world. If the art school is to be the heterotopic space it promises, it should strive to unsettle and rupture entrenched paradigms. Might we understand this rupture as part of a lineage of historical ruptures to dominant orthodoxies of art education - there have been times when women at art schools were deemed decorative, and working class youth as wholly unsuitable. Just as the presence of those outside of the canons of art made palpable the limitations of those paradigms, today, international students offer access to multiple cultural perspectives that can challenge the 'universalism' of Western teaching and learning practices (Ryan 2011).

What might happen if such approaches were adopted within a fine art programme? How might conversation as to the differences as well as similarities between education systems help to challenge our assumptions of others and even prompt an understanding of what art education is. In addressing itself as an educational institution might the art school produce the conditions to recognize and challenge established orthodoxies, and in so doing contribute to shaping art practices in the world?

\section{Conclusion}


The influx of international students within fine art contexts presents a challenge to the pre-existing orthodoxies, habitual ways and implicit values embedded there. As a result the equilibrium of the art school is indeed ruptured but this rupture need not be a threat. Rather, the presence of international students makes palpable the horizon of our paradigms and orthodoxies, prompting an examination as to how these have been constructed, are manifest and why they prevail. Harnessing the potential of this shift requires the UK art school to become more reflective of its own pedagogies and more interested in those of the students who study there. And whilst de stabilizing, this is necessary and potentially transformative too, and might even constitute the heterotopia that art school promises to be.

\section{References}

Austerlitz, N.,Vaughn, S. Blythman, M., Grove-White, A., Jones, B., Jones, C., Morgan, S., Orr, S. and Shreeve, A. (2009) Mind the Gap: Expectations, ambiguity and pedagogy Experience in Art and Design Higher Education, in L. Drew (Ed) The Student Experience in Art and Design Higher Education: Drivers for Change. Cambridge: Jill Rogers Associates Limited.

Banks, M. (2007) The Politics of Cultural Work. Palgrave Macmillan UK.

Bourdieu, P (1993) The Field of Cultural Production. Cambridge: Polity Press. 
Cortazzi, M. \& Jin, L. (1997) Expectations and Questions in Intercultural Classrooms, Intercultural Communication Studies, V11-2 1997.

Craig-Martin, M (2015) On Being an Artist. London: Art/Books

Curtis, A. (2014) Bitter Lake. video documentary accessed 20.02.16

http://www.bbc.co.uk/iplayer/episode/p02gyz6b/adam-curtis-bitter-lake

Elkins, J. (2001) Why Art Cannot be Taught. Illinois: University of Illinois Press.

Fisher, E. \& Fortnum, R. (2013) On Not Knowing; How Artists Think. London: Black Dog Publishing.

Helguera, P (2011), Education for Socially Engaged Art: A Materials and Techniques Handbook. Jorge Pinto Books

Den Heyer, Kent (2010) Thinking Education through Alain Badiou. Wiley Blackwell

Higher Education Statistics Agency website, 2013, accessed 28.02.16

https://www.hesa.ac.uk/finddata

Jackson, M. (2013) The Squeezed Middle: An exploration of creativity, conformity and social class on the academic achievement of undergraduate students within a UK art school, International Journal of Art and Design Education, Vol 32, No 3, pp. 345-351. 
Mitta, P. (2008) Decentering Modernism: Art History and Avant Garde Art from the

Periphery, The Art Bulletin, Vol. 90, No. 4, pp. 531-548.

O’Reilly, S. (2015) ‘Ambiguity’, A talk at Open School East, The Bad Vibes Club.

Ryan, J. (2011) Teaching and learning for international students: towards a transcultural approach, Teachers and Teaching, Vol. 17, No. 6, pp. 631-648.

Shepley, A. (2016) 'Art Schools as Heterotopias', Keynote at The Hidden Curriculum, National Association for Fine Art Education Annual Symposium.

Tickner, L. (2008) Hornsey 1968: The Art School Revolution. London: Francis Lincoln Ltd.

University of Westminster Mixed Media Fine Art BA Course Handbook Learning Outcomes, 2012 - ongoing

\footnotetext{
${ }^{\mathrm{i}}$ Press release for Fig.2 at the ICA https://www.ica.org.uk/whats-on/seasons/fig-2

ii Bottom Natures, a 2015 exhibition curated by Matthew McQuillan claims to rely on "an anti-auratic, anti-cynical tedium that at times deliberately risks seeming obtuse, as opposed to making claims for spiritual transcendence or ironic distance [...] What happens when a work hugs too tight; when it refuses to grant the viewer the distance for a cool, detached reading? Or when a work overloads; when it showers information, references and signifiers upon the casual bystander? The exhibition features [...] works that deploy repetition, humour, ambiguity, and contradiction to muddy the viewer's reading"

iii Curating and the Educational Turn published in 2010 by De Appel is one of a plethora of publications in recent years addressing the interrelations between pedagogy and art practice
} 